\title{
Valor da Empresa: Avaliação de Ativos pela abordagem do resultado Econômico Residual
}

Fabio Frezatti

Professor do Departamento de Contabilidade Atuaria - FEA/USP

Doutor em Controladoria e Contabilidade - FEA/USP

Mestre em Administração de Empresas - FEA/USP

Os autores clássicos de finanças sempre foram incisivos ao considerar que o grande adjetivo financeiro dos gestores das empresas é o proporcionar aumento de valor para os acionistas.Isto só o ocorre quando as decisões implementadas pela organização são entendidas como adequadas pelo mercado, aumentando a atratividade das ações e, como conseqüência, valorizando-as no mercado. Dessa, forma o que interessa para o acionista é que o seu investimento proporcione retorno que contemple risco e timing de reposição pelo tempo decorrido.

Nessa linha de raciocínio, do lado interno da empresa, alguma técnica deve ser disponibilizada para analisar, avaliar e permitir o direcionamento das decisões som o objetivo de proporcionar o acréscimo de saía o investimento feito pelo acionista. Por se tratar de conceito de obtenção futura, ou seja, valor é um conceito ligado às ocorrências a transcorrer, embora possa depender de doações que tenham ocorrido no passado, grande tem sido a dificuldade no monitoramento. Significa dizer que o valor da empresa deve ser planejado, constituindo-se em principal meta do plano estratégico da organização.

Aceitando-se que a valorização do investimento do acionista é importante e deve ser Planejada, quais indicadores são adequados para o seu monitoramento para o seu monitoramento? Rappaport (1908, p.13) menciona que algumas empresas utilizam dados contábeis, tais somo lucro/ação e retorno sobre o investimento como indicadores de aumento do valor, enquanto que outras se prendem ao fluxo no caixa gerado.

Levando em conta a disponibilidade, de várias metodologias e, em especial, daquela denominada Resultado Econômico Residual, este artigo foi desenvolvido com os seguintes objetivos:

1. apresentar as varias metodologias:

2. caracterizar a metodologia escolhida (abordagem do Resultado Econômico Residual): e

3. indicar as dificuldades referentes aos critérios possíveis, considerados por vários autores, na apuração do Resultado Econômico Residual.

\section{Abordagens Disponíveis}

Hendriksen (1992, p.121) considerou que os relato rios gerados pela contabilidade “(...) 
existem para suportar decisões aos acionistas e outros agentes nas suas decisões financeiras, a fim de projetar o fluxo de caixa corporativo." Sem esgotar o assunto, o Quadro 1 tem por pretensão identificar as várias vertentes conceituais, encontradas no momento, tratando o tema: valor de empresas.

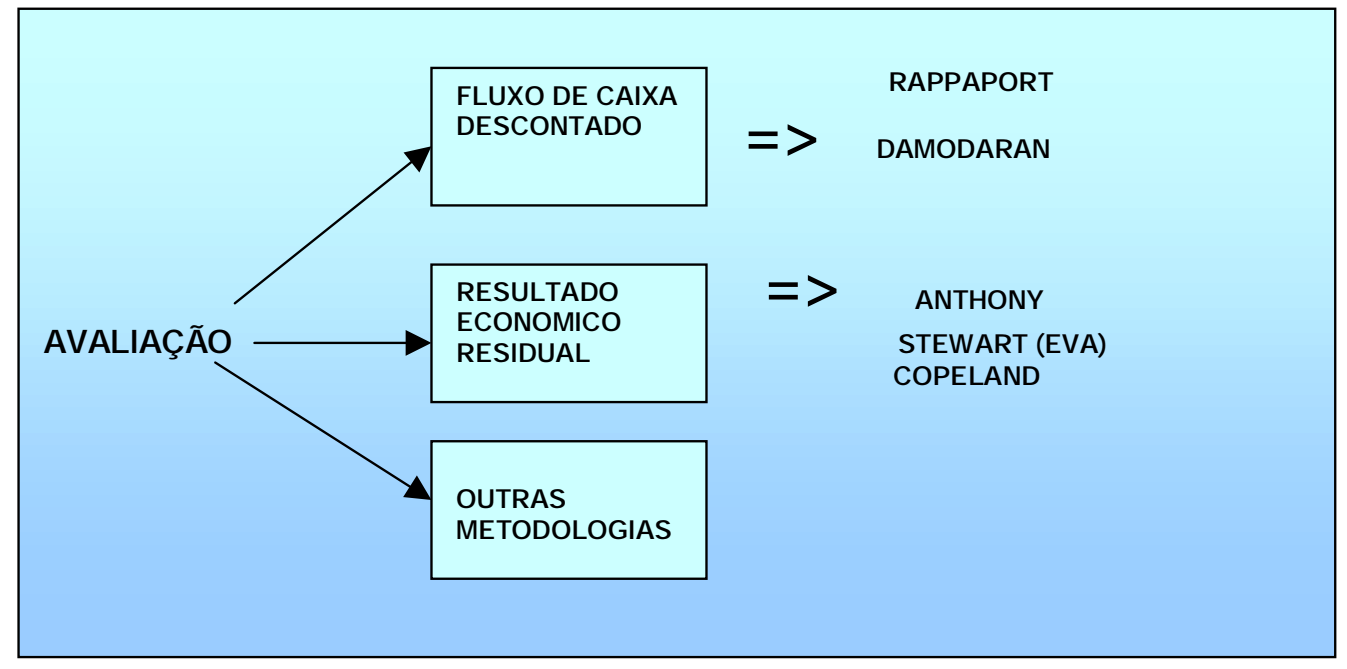

Levando em conta esse objetivo, podem ser percebidas três grandes linhas de pensamento. não necessariamente mutuamente exclusivas, que são:

\section{Abordagem do}

Fluxo de Caixa Descontado

Leva em conta a identificação do fluxo de caixa da empresa para o período futuro descontado pela sua taxa do custo de oportunidade. Adicionalmente, inclui o conceito de perpetuidade e/ou de ajustes pela inclusão de eventuais valores não operacionais. A metodologia tem sido utilizada desde longa data, mormente na avaliação de investimentos operacionais internos a empresa. Seu grande expoente no momento é o consultor Damodaran, muito embora Rappaport tenha importantes contribuições nessa área. Essa metodologia é a que se utiliza na avaliação de empresas no processo de privatização brasileiro da década de 90 . Este artigo não tem por objetivo aprofundar esta análise.

\section{Abordagem dos Múltiplos}

Abordagem mais comum nas decisões de investimento dos acionistas minoritários, baseiase no relacionamento entre variáveis, por exemplo, o índice Preço/Lucro, uma espécie de payback, que permite identificar pontos de entrada e saída do mercado. Analogamente ao item anterior, este assunto não será aprofundado neste artigo.

\section{Abordagem do Resultado Econômico Residual}

Esta abordagem persegue o resultado econômico, ou seja, o resultado operacional, liquido 
Valor da Empresa: Avaliação de Ativos pela Abordagem do Resultado Econômico Residual

do imposto de renda mas não afetado pelo custo de financiamento das operações. Diferentemente das abordagens anteriores, permite a análise distinta da operação, financiamento e gestão do investimento da organizacão. Stewart e, no momento, o estudioso mais importante, tendo introduzido o conceito sob o nome de EVA (Economic Value Added), muito embora o tema tenha sido motivo de preocupações por parte de David Ricardo, Marshall, Anthony, Schmalenbach e outros, incluindo outras visões e alternativas. Por esse motivo o termo Resultado Econômico Residual será utilizado, neste artigo, no sentido de identificar a família metodológica que incluí o EVA. O Resultado Econômico Residual. doravante denominado simplesmente de RER. será privilegiado neste artigo, tendo alguns méritos difíceis de serem refutados:

a) Linguagem conceitual simplificada:

Muito embora o conceito de resultado líquido após a remuneração não seja algo novo, o grande mérito de Stewart foi a simplificação da linguagem, tornando factível e praticável uma abordagem até então considerada puramente acadêmica e por demais complexa.

b) Não implica em ruptura mas sim agregação de conceitos: A utilização da base contábil é essencial para o cálculo dos valores necessários. Dessa maneira, o RER constitui-se em produto adicional da Contabilidade e não seu concorrente.

c) Um único instrumento atende a vários interesses:

Pode-se separar os interesses dos agentes em:

- Análise do desempenho interno da organização:

Pode ser obtida a partir do momento em que ela atrela todos os seus instrumentos de planejamento ao RER. A sua utilidade está ligada á gestão do negócio e as políticas de remuneração das organizações: cada vez mais estão ligadas a esse indicador.

-Análise de investimento:

Consiste na utilização da metodologia para projetar o resultado de uma organização para fins de aquisição, fusão ou mesmo o direcionamento de seus investimentos futuros no ativo permanente.

-Análise do mercado:

Situação verificada quando o analista externo, a partir das demonstrações contábeis publicadas e informações complementares da empresa, elabora o cálculo RER com finalidade de estabelecer 0 ranking e análise comparativa de desempenho Bacidore (1997, p.19) se revela entusiasmado com a correlação entre o EVA gerado e o retorno obtido pelas ações.

d) Apura o resultado que remunera realmente todos os acionistas stakeholders envolvidos, levando em conta o risco:

O resultado liquido após remuneração aos fornecedores, empregados, governo, credores ligados a instituições financeiras e acionista é de grande importância, pois indica o que realmente sobra para a entidade, o que realmente torna a entidade mais saudável e rica.

e) Benchmarking quando usado para análise externa:

A publicação do cálculo do RER decomposto em capital investido, retorno operacional e custo de capital permite ao analista externo entender o desempenho da organização em termos operacional, financeiro e de gestão dos seus investimentos.Tal disponibilidade faz com que a análise possa ser centrada nos pontos fortes e fracos de cada organização. Em uma dada empresa, por exemplo, o custo de capital pode se apresentar acima da média do seu setor, enquanto a rentabilidade se apresenta na média. De posse desse tipo de informação, o gestor pode identificar o seu benchmarking e perseguir melhoria de desempenho exatamente aonde se considera não suficientemente forte. 
Valor da Empresa: Avaliação de Ativos pela Abordagem do Resultado Econômico Residual

Se por um lado as vantagens existem, por outro, algumas limitações e mesmo dificuldades persistem, sendo que algumas das mais relevantes descritas a seguir:

a) Subjetividade dos critérios superior ao que os contadores estão acostumados a encontrar:

Os critérios de elaboração podem se alterar em função do tempo e perspectiva. Por exemplo, o valor total da Provisão para Devedores Duvidosos, constituída em um dado período, pode representar um valor maior do que o estritamente necessário, tendo como conseqüência, na metodologia, seu valor somado de volta ao lucro do período: em outro momento, essa conta deixa de ser somada em função de que esteja refletindo exatamente o nível de risco que se espera pela constituição.

Diferentes autores e diferentes tratamentos para as mesmas contas podem trazer como conseqüência valores distintos para as mesmas contas. Isto pode ser percebido com a receita financeira, por exemplo. Para alguns autores ela faz parte do resultado operacional e para outros não.

- Custo de oportunidade como novo elemento a tratar:

No lugar dos juros incorridos pelos recursos de terceiros captados, existe o cálculo do custo ponderado de capital a ser remunerado pela organização. Esse conceito, por se tratar de uma abordagem que necessita de premissas sobre a participação de cada tipo de recurso (próprios e de terceiros), é menos objetiva para o contador, implicando em potencial de grande amplitude de variação de resultados.

- Dificuldade no entendimento do que significa o resultado econômico:

Muito embora o resultado econômico tenha por característica a indicação do potencial de caixa a ser gerado, o entendimento do que representam os seus componentes nem sempre é simples. 0 resultado econômico não corresponde necessariamente ao fluxo de caixa gerado no período, nem mesmo é o lucro contábil. Dessa maneira, o tratamento da depreciação como fluxo econômico, por exemplo, é algo que pode gerar dúvidas nos profissionais.

- Dilema entre simplicidade e entendimento versus complexidade e precisão:

A simplificação dos critérios pode reverter em uma significativa imperfeição, frente à demanda da organização. Por outro lado, excessivo detalhamento ou ajustes para adaptação ou mesmo variabilidade dos critérios perante situações encontradas faz com que a confiabilidade no sistema dependa enormemente da capacidade de julgamento das pessoas.

Se a metodologia do RER e útil e permite gerenciar certos problemas críticos no relacionamento da organização com os stakeholders mais expressivos (os acionistas, o governo, os credores e os executivos), quais os motivos que fazem com que a sua utilização seja ainda pequena? A resposta a essa pergunta esta ligada as limitações apresentadas, que, na visão de muitos profissionais, não são superadas pelas suas vantagens. Como se percebe, ao levar em conta os aspectos mencionados, os critérios na operacionalização da metodologia são criticas na utilização do instrumento e podem ter tratamento distinto pelos vários autores.

Considerando-se que o método em si é adequado, constitui-se em ação de grande importância tratar os critérios de maneira que possam ser corretamente entendidos, testados e, eventualmente, utilizados. Para permitir que se conheça tal metodologia, este texto contemplará o seguinte roteiro: antecedentes históricos, conceituação dos elementos requeridos na apuração ao 
Valor da Empresa: Avaliação de Ativos pela Abordagem do Resultado Econômico Residual

RER, diferentes entendimentos dos critérios. exemplificação do calculo do RER e conclusões.

\section{Antecedentes Históricos}

O tema não se constitui em novidade conceitual, já que vem sendo tratado desde longa data, contudo, e evidente que durante muito tempo a grande preocupação aos autores estava restrita a contribuições conceituais, sem se ater a aplicação das mesmas, o que dificultou a sua aceitação e propagação. Atualmente, a visão mais pragmática permite a aplicabilidade, discussão e mesmo o aperfeiçoamento da metodologia.

David Ricardo, cuja obra apresenta vivências do final do século XVIII e do inicio do século XIX. e citado como um dos primeiros a se aproximar da figura do RER. Discordando das abordagens de Adam S mith, ele considerou:

"Algumas minas de carvão, embora vantajosamente localizadas, não podem ser exploradas por serem pobres, A produção não compensa os gastos. Elas não proporcionam nem lucro nem renda. Existem algumas cuja produção proporciona 0 estritamente necessário para pagar o trabalho e repor, conjuntamente com os lucros correntes, o capital empregado na sua exploração. Elas proporcionam algum lucro para quem as explora, mas não proporcionam renda ao proprietário. Elas não poderão ser exploradas sem prejuízo a não ser pelo proprietário que, explorando diretamente a mina, obtém o lucro normal pelo capital nela aplicado (...). 0 proprietário não permitiria que ninguém as explorasse sem pagar certa renda, mas ninguém teria condições de pagála."(Ricardo, 1982. p.222).

Muito embora Ricardo não esteja preocupado com diferenciação de recursos, ele trata a remuneração do capital empregado sob a forma de capital operacional (no caso a mina), com uma clara visão de utilização de recursos.

Schmalenbach (1961, p.I 80) trata o tema, calculando o custo do capital próprio como um componente a ser identificado no cálculo do lucro do período.

Marshall é citado por Copeland (1995, p. 149) como sendo aquele que definiu o conceito de resultado econômico. Em 1890, ele assim expressou o importan ${ }^{1}$ te conceito :" What remamns of his (the owner or manager's) profits after deducting interest on his capital at the current rate may be called his earnings of undertakíng or mana gement".

Como se percebe, Marshall não estava questionando quais elementos deveriam ser expurgados dos valores contábeis, mas sim considerava necessário o tratamento do custo de capital a ser aplicado sobre o resultado contábil apurado. Em outras palavras, os critérios para o seu cálculo deixam de ser seu objetivo de tratamento, embora ele perceba a necessidade de apurar resultado após a consideração de remuneração de todos os agentes. Tais critérios, serão objeto de análise no tem que tratará sobre as diferenças existentes a partir de observações dos autores citados, e

${ }^{1}$ Em se tratando de um conceito virtal ao adequado entendimento do tema, por uma questão de possibilitar maior transparência, o texto não foi traduzido 
Valor da Empresa: Avaliação de Ativos pela Abordagem do Resultado Econômico Residual

proposição do autor deste artigo.

Anthony, desenvolveu o critério do Residual Income (RI), posteriormente utilizado pela General Electric na década de 50, usando os conceitos de apuração de resultado em que a remuneração pelo capital investido era um clara percepção em termos de objetivo a se atingir. Ele definiu o RI como sendo um valor que se obtém ao subtrair do lucro o custo do capital investido, tal custo de capital é obtido mediante a multiplicação do valor dos ativos empregados por uma dada $\operatorname{taxa}^{2}$ (1984. p.344). Como se percebe, analisando a obra de Anthony, tal taxa não é o custo ponderado de capital (1984, p. 355), mas sim uma taxa próxima, que possa até diferenciar os vários riscos implícitos nos ativos da empresa.

Constitui-se em árduo trabalho identificar a seqüência cronológica do desenvolvimento dos conceitos, haja vista a existência de depoimentos próprios difíceis de serem comprovados e diferentes formas de exteriorização desses mesmos conceitos. Para fins deste artigo, o autor optou pela seqüência de publicações de livros como referencial cronológico, ignorando a existência de prováveis artigos que possam anteceder tais livros publicados.

Nesta linha de raciocínio, Rappaport, em 1986 publica sua obra Creating ShareholderValue ${ }^{3}$. obra em que propõe metodologia para apuração do Resultado Econômico (por ele denominado Shareholder Value Added), muito embora ele mesmo não se classifique como tal (1998. p.122). Seu tratamento, em termos de modelo matemático, e de grande detalhamento e profundidade, sendo reconhecido como um importante passo dentro das pesquisas sobre o tema.

Apesar de argumentar que desde 0 final da década de 60 estaria envolvido com o tema, principalmente no que se refere ao conceito de fluxo de caixa livre. Stewart, só em 1991, Lança o livro The Quest of Value, a partir de uma abordagem relativamente simplificada da aplicação de conceitos relacionados com o Resultado Econômico Residual. 0 fato de, como analista externo, ter apurado os resultados das empresas americanas ${ }^{4}$ deu um impulso muito grande à metodologia, já que isso não era adequadamente explorado, 0 termos Economic Value Added (EVA) e Market Value Added (MVA) são por ele cunhados e patenteados, sendo citado Rappaport, o primeiro acadêmico a apoiar a abordagem. A implantação da metodologia na Coca-Cola foi um passo importante na fase do depoimento sobre a eficácia da metodologia e o sucesso atingido por tal empresa foi particularmente atribuído à adequação do EVA.

Em 1995. Copeland lança seu livro Valuation: measuring and managing the value of companies, em que retoma as abordagens de Stewart e amplia a utilidade para a metodologia.

Em 1995, a Tillinghast-Towers Perrin (Níedzielski, 1995. p. 4) desenvolve uma pesquisa no ambiente norte-americano e afirmou que cerca de $7 \%$ das empresas participantes da sua amostra utilizavam o EVA como medidor de desempenho., enquanto cerca de $14 \%$ utilizavam a metodologia para análise de investimentos.

\footnotetext{
2 Tradução-livre feita pelo autor deste artigo.

3 Obra revisada, em nova edição de 1998.

${ }^{4}$ Trata-se de análise das 1000 maiores empresas dos Estados Unidos
} 
Conceituação dos Elementos Requeridos na Apuração do Resultado Econômico Residual (RER)

De maneira simplificada, o RER é aquilo que sobra para a empresa depois que ela remunera, paga, retorna, recursos consumidos no seu processo, Tal remuneração/pagamento /retorno envolve 0 acionista, instituições financeiras, fornecedores, empregados e prestadores de serviços. O cálculo do RER é desenvolvido a partir da apuração das seguintes figuras: (RODIR/ Cl$\mathrm{CPCE}) \times \mathrm{Cl}$, onde pode-se conceituar:

1. Resultado operacional depois do imposto de renda (RODIR):

Corresponde ao resultado apurado a partir do resultado líquido contábil após o imposto de renda e devidamente ajustado pelos valores a expurgar, tais como:

- despesas de juros líquidos dos efeitos do imposto de renda derivado da existência das despesas de juros:

- apropriações de gastos que já ocorreram no passado e que possam ter beneficio futuro;e

- provisões cuja perspectiva de afetar o caixa seja próximo de zero.

Por sua vez, a depreciação não é expurgada do resultado, porque corresponde à figura da amortização econômica e deve ser recuperada. Se fosse expurgada revelaria o nível de margem que não seria suficiente para repor os investimentos feitos no imobilizado.

2. Capital investido $(\mathrm{Cl})^{5}$ :

Corresponde aos recursos necessários para que a organização possa desenvolver suas atividades operacionais. Considera-se que o grau de eficiência a obter seja função do desempenho na gestão dos elementos contidos. Pode ser calculado tanto pelo critério de identificação dos investimentos feitos na operação (capital de giro operacional adicionado ao permanente menos os passivos não onerosos de longo prazo), como também pelos financiamentos obtidos (empréstimos de curto e longo prazos, provisões e patrimônio liquido). Os gastos já incorridos, tais como pesquisa e desenvolvimento apropriados ao resultado e que ainda não geraram produtos a faturar, deveriam voltar para o Ativo, de maneira capitalizada (Stewart. 1991, p. 29). Por sua vez, a amortização do goodwill (S tewart 1991, p. 25), por exemplo, deve ser apurada e deve ser adicionada ao investimentos ${ }^{6}$; e

3. Custo ponderado de capital da empresa

(CPCE):

Composto pela ponderação dos recursos que financiam as operações da organização, tanto recursos próprios como de terceiros. No que se refere aos recursos próprios, ou seja, adequados que estão no Patrimônio Liquido, são considerados à luz do risco existente, sendo que o retorno deve recompensar o investidor pelo risco incorrido, diferenciado por meio do beta apurado.

O MVA corresponde à diferença entre o Valor de Mercado da empresa menos o Capital

\footnotetext{
${ }^{5}$ Traduzido literalmente em função de se constituir, em inglês, num termo consagrado.

6 comentário do autor citado refere-se exclusivamente à realidade de seus pais, em que tais valores são tratados como gastos do período e não capitalizados. No caso brasileiro, é possível encontrar esse tratamento e outro, que trata Pesquisa e Desenvolvimento como gasto capitalizado.
} 
Valor da Empresa: Avaliação de Ativos pela Abordagem do Resultado Econômico Residual

Investido. Corresponde, no entender de Stewart, ao fluxo de RER's projetados para o futuro, trazidos a valor presente e ajustados pelos valores não operacionais e mesmo capital de giro financeiro. Esse indicador tem serventia ao identificar as empresas que o mercado considera como criadoras de riqueza (valor) para a organização, separando-as daquelas que o mercado não considera como criadoras de riqueza.

\section{Diferentes Entendimentos dos Critérios}

Como citado, a abordagem de análise de valor, denominada RER, engloba várias vertentes que possuem grandes semelhanças e algumas divergência. Entender as divergências é uma das dificuldades encontradas, quando se pretende desenvolver a metodologia em uma dada organização. já que o RER constitui-se em um elemento que se diferencia daqueles por eles usualmente conhecidos. Em outras palavras, ele não é exatamente fluxo de caixa, nem mesmo resultado contábil. 0 importante em termos de critério é que o RER deve se aproximar do caixa gerado (ou a ser gerado) em dado horizonte. Para obtê-lo, certos ajustes devem ser feitos ao resultado contábil, o que será o ponto de partida para chegar ao Resultado Operacional Depois do Imposto de Renda - RODIR.

Dessa forma, a metodologia tem que recorrer a base de dados da contabilidade para obter as informações básicas e, a partir dela, efetuar ajustes, Levando em conta que, a obtenção do resultado possa refletir a geração de riqueza da organização, o Quadro 2 reflete a opinião de autores que tratam o tema, em alguns casos, divergindo suas opiniões sobre o que deve ser ajustado para permitir a obtenção do resultado econômico. Dentre os que mais contribuíram para tal, foram escolhidos Stewart e Copeland.

\begin{tabular}{|l|l|l|l|}
\hline Elementos & Stewart & Copeland & Proposta \\
\hline $\begin{array}{l}\text { Despesas de J uros de curto e } \\
\text { longo prazo }\end{array}$ & $\begin{array}{l}\text { Somar ao lucro } \\
\text { líquido contábil }\end{array}$ & $\begin{array}{l}\text { Critério igual ao } \\
\text { apresentado por } \\
\text { Stewart }\end{array}$ & $\begin{array}{l}\text { Critério igual ao } \\
\text { apresentando para } \\
\text { Stewart }\end{array}$ \\
\hline $\begin{array}{l}\text { Impacto do imposto de renda } \\
\text { sobre os juros de curto e } \\
\text { longo prazos }\end{array}$ & $\begin{array}{l}\text { Subtrair do } \\
\text { resultado } \\
\text { considerando o } \\
\text { efeito sobre } \\
\text { despesas }\end{array}$ & $\begin{array}{l}\text { Subtrair do resultado } \\
\text { considerando o efeito } \\
\text { sobre receitas e } \\
\text { despesas }\end{array}$ & $\begin{array}{l}\text { Critério igual ao } \\
\text { apresentando para } \\
\text { Stewart }\end{array}$ \\
\hline Apropriação da Depreciação & $\begin{array}{l}\text { Não altera o } \\
\text { resultado contábil }\end{array}$ & $\begin{array}{l}\text { Critério igual ao } \\
\text { apresentado p/ } \\
\text { Stewart }\end{array}$ & $\begin{array}{l}\text { Critério igual ao } \\
\text { apresentando para } \\
\text { Stewart }\end{array}$ \\
\hline $\begin{array}{l}\text { Amortizações de ativos com } \\
\text { vida útil formalmente } \\
\text { definitiva }\end{array}$ & Omitido & $\begin{array}{l}\text { Não altera o resultado } \\
\text { contábil }\end{array}$ & $\begin{array}{l}\text { Não altera o } \\
\text { resultado contábil }\end{array}$ \\
\hline $\begin{array}{l}\text { Provisões com baixo } \\
\text { potencial de concretização }\end{array}$ & $\begin{array}{l}\text { Somar ao lucro } \\
\text { líquido contábil }\end{array}$ & $\begin{array}{l}\text { Critério igual ao } \\
\text { apresentado por } \\
\text { Stewart }\end{array}$ & $\begin{array}{l}\text { Critério igual ao } \\
\text { apresentado por } \\
\text { Stewart }\end{array}$ \\
\hline $\begin{array}{l}\text { Provisões que, em } \\
\text { decorrência do tempo podem } \\
\text { se concretizar }\end{array}$ & Omitido & Omitido & $\begin{array}{l}\text { Não altera o } \\
\text { resultado contábil }\end{array}$ \\
\hline Gastos com pesquisa e & Somar ao liquido & Excluir tanto o valor & Critério igual ao \\
\hline
\end{tabular}


Valor da Empresa: Avaliação de Ativos pela Abordagem do Resultado Econômico Residual

\begin{tabular}{|c|c|c|c|}
\hline desenvolvimento & contábil & $\begin{array}{l}\text { do ativo como a } \\
\text { parcela que foi para } \\
\text { resultado }\end{array}$ & $\begin{array}{l}\text { apresentado por } \\
\text { Stewart }\end{array}$ \\
\hline Receitas financeiras & Omitido & $\begin{array}{l}\text { Excluir do lucro } \\
\text { líquido contábil }\end{array}$ & $\begin{array}{l}\text { Não altera o } \\
\text { resultado contábil }\end{array}$ \\
\hline Amortização do Goodwill' & $\begin{array}{l}\text { Somar ao lucro } \\
\text { líquido contábil }\end{array}$ & $\begin{array}{l}\text { Excluir tanto o valor } \\
\text { do ativo como a } \\
\text { parcela que foi para } \\
\text { resultado }\end{array}$ & $\begin{array}{l}\text { Critério igual ao } \\
\text { apresentado por } \\
\text { Stewart }\end{array}$ \\
\hline $\begin{array}{l}\text { Leasing operacional levado a } \\
\text { resultado }\end{array}$ & Omitido & $\begin{array}{l}\text { Apitalizar e apropriar } \\
\text { depreciação }\end{array}$ & $\begin{array}{l}\text { Não altera o } \\
\text { resultado contábil }\end{array}$ \\
\hline Equivalência patrimonial & Omitido & Omitido & $\begin{array}{l}\text { Somar ao lucro } \\
\text { líquido contábil }\end{array}$ \\
\hline Resultados não repetitivos $^{9}$ & Omitido & $\begin{array}{l}\text { Somar ao lucro } \\
\text { líquido contábil }\end{array}$ & $\begin{array}{l}\text { Somar ao lucro } \\
\text { líquido contábil }\end{array}$ \\
\hline $\begin{array}{l}\text { Ajustes nos custos e } \\
\text { estoques }\end{array}$ & $\begin{array}{l}\text { Ajustes do tipo FIFO } \\
\text { para médico } \\
\text { somados ao lucro } \\
\text { contábil }\end{array}$ & Omitido & $\begin{array}{l}\text { Somar ao lucro } \\
\text { líquido contábil, } \\
\text { quando não indica } \\
\text { potencial de caixa }\end{array}$ \\
\hline
\end{tabular}

Quadro 2: Diferentes Abordagens dos Estudiosos do Tema Valor Residual

Complementando, o autor deste artigo incluiu uma coluna (intitulada de "Proposta") para expressar a sua opinião sobre o tratamento de algumas linhas em que diverge do entendimento dos autores mencionados. Como se percebe, nos pontos destoantes se circunscrevem: as receitas de juros, as amortizações de ativos com vida útil formalmente definida (patentes e franchising), os gastos com pesquisa e desenvolvimento, o goodwill, o leasing operacional, a equivalência patrimonial e os ajustes nos estoques.

As divergências de critérios, como decorrência do próprio cálculo do RODIR, também podem afetar a apuração do capital investido. O capital indica os recursos que foram aplicados na organização e que devem produzir os benefícios de geração de riqueza. Pode ser calculado a partir dos recursos propriamente ditos, por exemplo: capital de giro operacional+ realizável + permanente passivo não oneroso de longo prazo, ou então, a partir do seu complementar em termo de contas de balanço, tais como: empréstimos e financiamentos de curto e longo prazos, patrimônio liquido e provisões. Nesse sentido, o Quadro 3 tem por objetivo identificar algumas das contas mais importantes.

\begin{tabular}{|l|l|l|l|}
\hline Elementos & Steward & Copeland & Proposta \\
\hline Investimentos no & Omitido & Considerado como & Considerado como \\
\hline
\end{tabular}

\footnotetext{
${ }^{7}$ Na realidade, o tratamento a ser dado para esse tipo de ativo requer uma analise mais apurada e especificada para çaracterizar sua amortização em função de uma data expectativa de vida útil.

${ }^{8}$ Embora se considere como critério geral, a única forma de se dispor de critério que faça sentido é considerar cada caso isoladamente: uma empresa que não tenha a distribuição de dividendos durante certo espaço de tempo estará se caracterizando frente ao critério.

${ }^{9}$ Quando o resultado futuro for projetado, deve ser excluído tanto o resultado não operacional como o não repetitivo.
} 
Valor da Empresa: Avaliação de Ativos pela Abordagem do Resultado Econômico Residual

\begin{tabular}{|l|l|l|l|}
\hline mercado financeiro & $\begin{array}{l}\text { não operacional, } \\
\text { reduzindo os } \\
\text { empréstimos }\end{array}$ & $\begin{array}{l}\text { resultado operacional } \\
\text { deixado, no } \\
\text { investimento }\end{array}$ \\
\hline $\begin{array}{l}\text { Despesas pré-pagas } \\
\text { apropriadas }\end{array}$ & Omitido & Omitido & $\begin{array}{l}\text { Voltar valores para o } \\
\text { ativo }\end{array}$ \\
\hline $\begin{array}{l}\text { Leasing operacional } \\
\text { pago }\end{array}$ & Omitido & Capitalizar & Não se altera \\
\hline
\end{tabular}

Quadro 3: Diferentes Abordagens dos Estudiosos do Tema Capital

\section{Exemplificação do Calculo do RER}

Tendo em vista permitir o entendimento da metodologia, foi elaborada exemplificação em que são calculadas as várias alternativas de critérios apresentados. Para tanto, demonstração de resultados e balanço apresentados em moeda de mesmo poder aquisitivo se constituem em requisitos iniciais (quadro 4 e 5 ).

\begin{tabular}{|l|c|}
\hline \multicolumn{2}{|c|}{ Demonstração do Resultado do Período } \\
\hline \multicolumn{2}{|c|}{ R\$ em moeda de poder aquisitivo de 31/12/x1 X1 } \\
\hline Receita Liquida & 6.500 \\
(-) Custo de produtos vendidos & 4.100 \\
(-) Provisão para ajustes & 50 \\
(-)Gastos com pesquisa e desenvolvimento & 30 \\
& \\
\hline Lucro Bruto & 2.320 \\
\hline (-) Despesas: & \\
& \\
Salários e encargos & 600 \\
Gastos com Comunicação & 300 \\
Provisão para devedores duvidosos & 30 \\
Provisão para contingências & 60 \\
Equivalência patrimonial & 200 \\
Outras despesas & 30 \\
& \\
\hline Total & 1.200 \\
\hline Resultado Operacional & 1.100 \\
& \\
(+) Outras receitas (+) e despesas (-) & 35 \\
(-) juros sobre o capital próprio & 35 \\
(+) Receitas de juros & 40 \\
(-) Despesas de juros & 118 \\
Resultado antes do IR & 757 \\
(-)IR & 250 \\
\hline Lucro Liquido após IR & 507 \\
\hline
\end{tabular}

Quadro 4

Caderno de Estudos, São Paulo, FIPECAFI, V.10, n.19, p.57 - 69, setembro/dezembro 199810 
Valor da Empresa: Avaliação de Ativos pela Abordagem do Resultado Econômico Residual

\begin{tabular}{|l|c|c|}
\hline \multicolumn{2}{|c|}{ Balanço Patrimonial } \\
\hline \multicolumn{2}{|c|}{ R\$ (em moeda de poder aquisitivo de 31/12/x) $31 / 12 / \times 0$} & $31 / 12 / \times 1$ \\
\hline Ativo & & \\
Caixa & 1 & 1 \\
Investimentos no mercado Financeiro & 200 & 35 \\
Contas a receber & 250 & 270 \\
- Provisão para devedores & -10 & -40 \\
Estoques & 500 & 420 \\
- Provisão para desvalorização de estoques & -10 & -15 \\
Outros circulantes & 100 & 100 \\
Total Ativo Circulante & 1.031 & 771 \\
Realizável a Longo Prazo & 50 & 50 \\
Investimentos em Controladas & 2.000 & 2.200 \\
Imobilizado Bruto & 6.680 & 6.970 \\
Depreciação Acumulada & -2.650 & -3.330 \\
Diferido & 300 & 270 \\
Total Permanente Líquido & 6.330 & 6.110 \\
\hline Total do Ativo & 7.411 & 6.931 \\
\hline Passivo e Patrimônio Liquido & & \\
& & \\
Fornecedores & 450 & 450 \\
Empréstimos & 2.341 & 876 \\
Outras contas a pagar & 134 & 250 \\
Provisão para contingências & 200 & 260 \\
Impostos a pagar & 21 & 250 \\
Outros passivos de curto prazo & 15 & 18 \\
Total passivo circulante & 3.161 & 2.104 \\
Passivos não Onerosos de Longo Prazo & 50 & 60 \\
Patrimônio Liquido & 500 & 560 \\
& 3.700 & 4.207 \\
\hline Total Passivo de Patrimônio Liquido & 6.931 \\
\hline
\end{tabular}

Quadro 5

O Quadro 6 apresenta o cálculo comparativo do RODIR, figura essencial para se obter o percentual de retorno operacional da entidade. 0 cálculo é iniciado pelo Lucro líquido da entidade, sendo efetuados os vários ajustes apresentados, conforme cada estudioso, 0 critério considerado foi aquele em que foram identificadas as definições de cada um deles. Nos casos omissos, ou seja, não tratados pelo autor, foi considerado que inexistiram ajustes ao lucro liquído.

Evidentemente que, o impacto sobre o resultado depende da magnitude dos elementos que possam trazer interpretação divergente, mas os cálculos demonstram, ao menos para o exemplo numérico apresentado, que a amplitude da variação dos resultados pode ser muito significativa. 
Valor da Empresa: Avaliação de Ativos pela Abordagem do Resultado Econômico Residual

\begin{tabular}{|l|l|l|l|}
\hline \multicolumn{2}{|c|}{ Em \$ 1000} & \multicolumn{2}{c|}{ Stewart } \\
\hline Lucro Liquido & 507 & 507 & 507 \\
+ Despesas de juros & 118 & 118 & 118 \\
(-) Ir sobre juros & -39 & -39 & -39 \\
+) uros sobre o capital próprio & 300 & 300 & 300 \\
(-) Ir sobre juros & -99 & -99 & -99 \\
-Receita de juros & -40 & - & - \\
(+) Ir sobre juros & 13 & - & - \\
+ Ajustes de estoques & - & 50 & 50 \\
+ Devedores duvidosos & 30 & 30 & 30 \\
+Provisão contingências & 60 & 60 & 60 \\
-Receita de Equivalência patrimonial & - & - & -200 \\
+Pesquisa e desenvolvimento & 30 & 30 & 30 \\
\hline =RODIR & 880 & 957 & 757 \\
\hline
\end{tabular}

Quadro 6 - Apuração do RODIR

No quadro 7 foram demonstrados os impactos dos diferentes critérios para o calculo do capital investido no negócio. Pode-se perceber a possibilidade de existirem ajustes feitos no RODIR mais significativos do que aqueles que são feitos no Capital Investido $(\mathrm{Cl})$

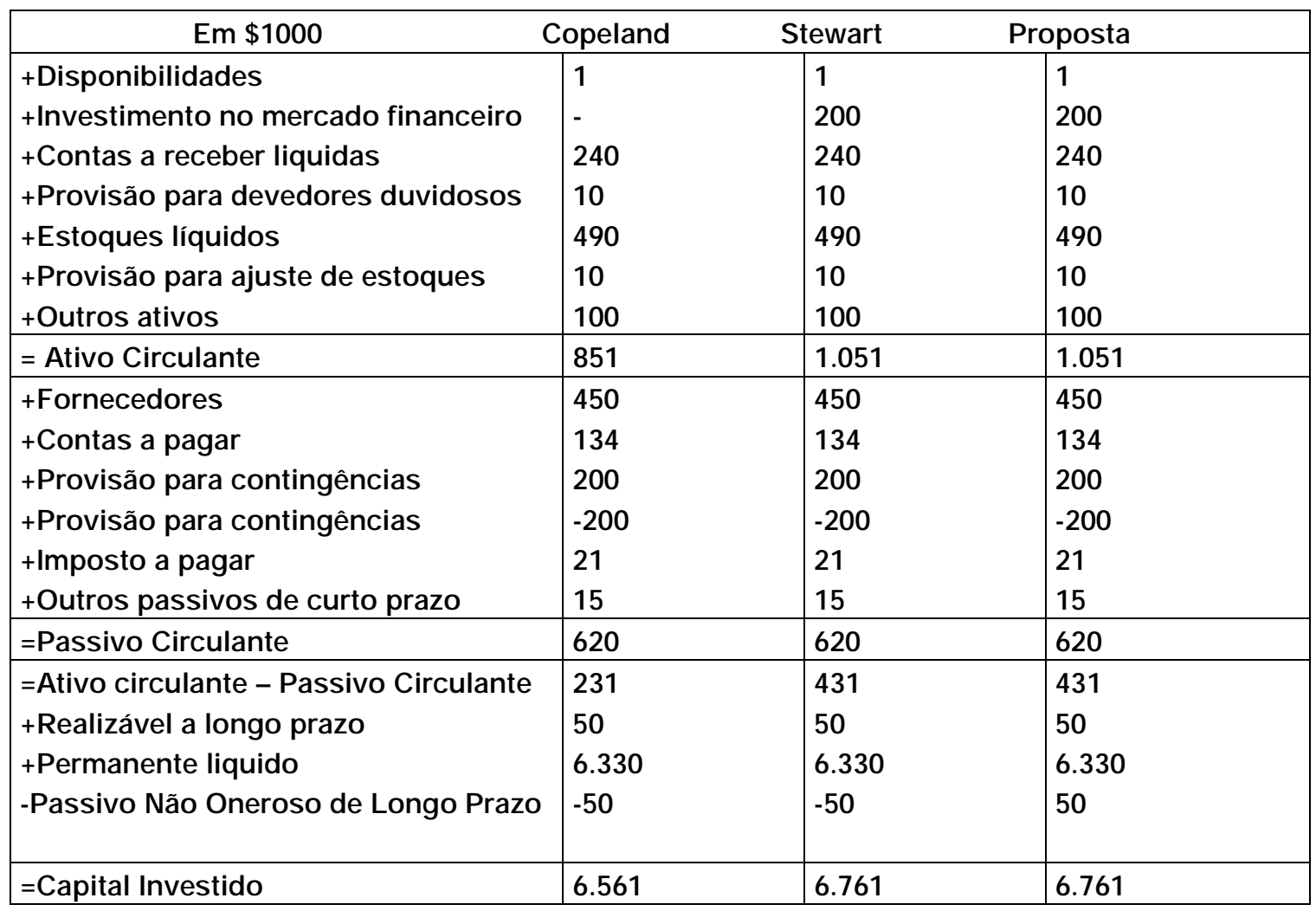

Quadro 7 - Apuração do Capital pela ótica Operacional

A taxa de retorno (quadro 8) é uma conseqüência da divisão RODIR pelos recursos que a entidade teve a sua disposição para operara no período (C apital investido).

Caderno de Estudos, São Paulo, FIPECAFI, V.10, n.19, p.57 - 69, setembro/dezembro 199812 
Valor da Empresa: Avaliação de Ativos pela Abordagem do Resultado Econômico Residual

Embora o retorno seja importante, mais importante do que ele é o spread, ou seja, a diferença entre a taxa de retorno obtida e o custo ponderado de capital incorrido (Quadro 9). Quanto maior o spread (Quadro 10), maior a condição de retorno a obter.

Copeland Stewart Proposta

\begin{tabular}{lccr}
\hline Em $\$ 1.000$ & & & \\
RODIR & 880 & 957 & 757 \\
Capital inicial & 6.561 & 6.761 & 6.761 \\
R & $13,4 \%$ & $14,1 \%$ & $11,2 \%$
\end{tabular}

Quadro 8 - Apuração da Taxa de Retorno (R)

\begin{tabular}{|l|r|r|}
\multicolumn{1}{c}{ Taxa } & \multicolumn{1}{c}{ Beta } & Prêmio \\
\hline \multicolumn{1}{c|}{$7,0 \%$} & 1,1 & $6,0 \%$ \\
\hline Custo ponderado de capital & & $13,6 \%$ \\
\hline & Target & Custo \\
\hline Capital próprio & $42,0 \%$ & $13,6 \%$ \\
Capital terceiros & $58,0 \%$ & $9,5 \%$ \\
Custo ponderado & $100,0 \%$ & $11,2 \%$ \\
\hline
\end{tabular}

Quadro 9 - Apuração do Custo Ponderado de Capital

O cálculo do resultado RER é demonstrado no Quadro 10, onde se percebe a influência dos critérios sobre o resultado final. Dessa maneira, ao deixar de considerar um dado elemento (a receita financeira, por exemplo), o impacto no resultado é desfavorável. Por outro lado, ao ignorar o efeito da equivalência patrimonial, por exemplo, o resultado se torna superestimado no que se refere a uma versão que a trata como não caixa.

Copeland Stewart Proposta

\begin{tabular}{|c|c|c|c|}
\hline $\begin{array}{l}\text { Capital inicial } \\
\text { R (retorno) }\end{array}$ & $\begin{array}{l}6.561 \\
13,4 \%\end{array}$ & $\begin{array}{l}6.761 \\
14,1 \%\end{array}$ & $\begin{array}{r}6.761 \\
11,2 \%\end{array}$ \\
\hline Custo Ponderado de Capital & $11,2 \%$ & $11,2 \%$ & $11,2 \%$ \\
\hline Spread & $2,2 \%$ & $2,9 \%$ &, $0 \%$ \\
\hline RER do ano & 144 & 196 & -1 \\
\hline
\end{tabular}

Quadro 10 - Apuração do RER

Ao analisar as três projeções, o tomador de decisão pode chegar à conclusão que a organização teve um ótimo desempenho (critério Stewart ou Copeland) ou então apenas se manteve "viva" (critério: Proposta), dependendo do encaminhamento adotado. A rigor, o fundamental nesse caso é que o responsável pelo seu cálculo tenha desenvolvido a sua modelagem refletindo a realidade da entidade e mantendo a consistência ao longo do tempo. 
Valor da Empresa: Avaliação de Ativos pela Abordagem do Resultado Econômico Residual

A projeção de resultados futuros deve ser feita de maneira muito mais profunda e detalhada do que o exemplo contido no Quadro 11 contudo, apenas para fechar o exemplo, em termos de potencial da metodologia, o resultado apurado em um dado exercício foi repetido, o fluxo futuro foi descontado pela taxa de custo de oportunidade da empresa e os ajustes foram feitos (ativos e passivos financeiros foram considerados). A comparação do resultado projetado (valor intrínseco) com o valor do mercado permite apurar o MVA, que indica o distanciamento entre a estratégia prevista da empresa e a percepção/aceitação do mercado (matematicamente é calculado a partir da diferença entre o valor de mercado e o capital investido, em bases unitárias). Quanto maior for esse valor, melhor para a entidade do ponto de vista da confiança e perspectiva de aumento de valor. Quanto mais negativo for, pior, já que revela percepção desfavorável em relação ao poder de gestão dos executivos.

\begin{tabular}{|c|c|c|c|c|}
\hline $\operatorname{Em~R} \$ 1.000$ & & Copeland & Stewart & Proposta \\
\hline Período & Fator & & & \\
\hline RER do ano 1 & 1.000 & 144 & 196 & -1 \\
\hline RER do ano 2 & 0,899 & 129 & 176 & -1 \\
\hline RER do ano 3 & 0,808 & 116 & 158 & -1 \\
\hline RER do ano 4 & 0,727 & 105 & 142 & -1 \\
\hline RER do ano 5 & 0,653 & 94 & 128 & -1 \\
\hline Perpetuidade do RER a valor presente & 0,653 & 840 & 1.156 & -9 \\
\hline Soma & & 1.426 & 1.956 & -14 \\
\hline \multicolumn{5}{|l|}{ Ajustes: } \\
\hline + Investimentos no mercado financeiro & & 200 & - & - \\
\hline -Empréstimos CP & & -2.341 & -2.341 & -2.341 \\
\hline - -Empréstimos LP & & -500 & -500 & -500 \\
\hline + Capital inicial & & 6.561 & 6.761 & 6.761 \\
\hline$=$ Valor da entidade para acionista & & 5.348 & 5.876 & 3.906 \\
\hline Numero de ações (em milhares) & & 100 & 100 & 100 \\
\hline Valor unitário da ação (intrínseco) & & 53,48 & 58,76 & 39,06 \\
\hline Valor unitário cotado no mercado & & 35,00 & 35,00 & 35,00 \\
\hline MVA (Market Value Added) - aceito pe & mercado & $-30,61$ & $-32,61$ & $-32,61$ \\
\hline MVA (Market Value Added) - visto pelo & analista & 18,48 & 23,76 & 4,06 \\
\hline
\end{tabular}

Quadro 11 - Apuração Do Retorno Econômico Residual Futuro

$\underline{\text { Conclusões }}$ Algumas conclusões/recomendações gerais ser oferecidas aos leitores deste artigo: Caderno de Estudos, São Paulo, FIPECAFI, V.10, n.19, p.57 - 69, setembro/dezembro 199814 
Valor da Empresa: Avaliação de Ativos pela Abordagem do Resultado Econômico Residual

1. Muito embora seja algo que não é novo em termos de concepção, haja vista a presença de tais conceitos na abordagem do controle gerencial da General Eletric, na década de 50 por exemplo, o tema tem sido tratado de maneira pouco entusiástica. Isso ocorre, principalmente, pelo fato de serem requeridos critérios que podem trazer diferentes interpretações, o que faz com que muitos profissionais não se sintam confortáveis frente à possibilidade de auditar e repetir tais fenômenos de maneira a não produzir distorções: entretanto, como se percebe, no tem que mostrou as diferentes abordagens de cálculos do RER, a metodologia é de grande utilidade no lado interno da empresa, pela possibilidade de separação da análise de desempenho em retorno operacional, custo do capital e investimentos efetuados. Por outro lado, permite que sejam desenvolvidas também análises externas à empresa, possibilitando gerenciar o valor da ação, pelo relacionamento entre valor do mercado, Capital Investido (Cl) e MVA:

2. Os critérios de estruturação da metodologia podem se converter em elementos simples ou complexos, dependendo das operações e conseqüentes contabilizações, dai derivando maior clareza ou dificuldade de entendimento. Contudo, ainda que mais complexo e, às vezes, arbitrário, o simples fato de considerar o custo de capital da organização seria o suficiente para proporcionar subsidies de grande utilidade para o gerenciamento do resultado, constituindo-se em importante instrumento para redução/eliminação da ambigüidade e dubiedade dos resultados a atingir:

3. A análise e o estabelecimento dos critérios para a apuração do RER devem levar em conta as peculiaridades de cada organização, requerendo definições provenientes do julgamento dos profissionais da empresa sobre a sua realidade. Nos exemplos numéricos apresentados, ficou patente o potencial de dispersão que diferentes critérios podem trazer à gestão da organização. Por se tratar de metodologia que, cada vez mais, terá relacionamento com avaliação de desempenho, não apenas a busca pelos critérios mais corretos, mas também o "disclosure interno", se faz necessário para que a entidade tenha amplos benefícios pela utilização do ferramental:

4. Considerar, tanto para decisões de investimento como análise de desempenho, ou mesmo análise externa, conceitos de faixa de variação no lugar de abordagem pontual, isto significa dizer que a entidade possa ter custo de capital oscilando entre 9 e 1100, por exemplo, o que deve gerar RER entre $\$ x$ e $\$ y$; e

5. Como conseqüência da variabilidade e forte impacto do julgamento sobre a definição dos critérios, a utilidade da metodologia como base para a análise externa a entidade (publicações de ranking, por exemplo) é mais propensa a divergências e críticas do que a utilidade interna, como instrumento de gestão e avaliação de desempenho.

$\underline{\text { Resumo }}$

O artigo discorre sobre a avaliação de empresas, considerando as várias metodologias disponíveis e detendo-se especificamente sobre uma delas, aqui denominada, Resultado Econômico Residual -RER.Tal metodologia, longe de ser uma novidade, e algo que vem sendo discutido durante muito tempo, tendo recebido muitas contribuições desde 0 inicio do século XIX. O ponto forte da 
Valor da Empresa: Avaliação de Ativos pela Abordagem do Resultado Econômico Residual

metodologia consiste na sua simplicidade conceitual e abrangência lógica, possibilitando a avaliação do desempenho operacional, financeiro e do montante de investimentos. Por outro lado, a sua grande vulnerabilidade é a necessidade de critérios de ajustes, que podem se tornar subjetivos face às peculiaridades encontradas nas organizações.

A metodologia pode ser usada para a análise interna de direcionamento de investimentos, avaliação de desempenho interna e análise externa. Pelas suas características, a última abordagem é aquela que maiores imperfeições pode gerar.

\section{Referências Bibliográficas}

ANTHONY, Robert N., DEARDEN, J ohn. BEDFORD, Norton. Management centrol systems. NewYork: Irwin, 1984.

BACIDORE. J effrey, BOQUIST, J ohn. MILBOUN, Todd \&THAKOR. Anjan.The search for the best financial performance measure. Financial Analyst J ournal, May/J une, 1997.

COPELAND. Tom et alii. Valuatíon: measuring ano managing the value of companies. New York: Wiley, 1.995.

HENDRIKSEN, Eldon \& BREDA. Michael. Accountíng theory. 5. ed. Boston: Irwin. 1992.

NIEDZIELSKI, J oe. Better new business appraisal needed by CEOs. Cincinati: National Underwriter Life \& Health Financial Sevices, 1995.

RAPPAPORT, Alfred. Creating shareholder value. NewYork: Free Press, 1998.

RICARDO, David. Princípios de economia política e tributação. São Paulo: Editora Victor Civita, 1982.

SCHMALENBACH, E. Le bilan dynamique. Dunod. Paris, 1961.

STEWART, G.Bennett. III. The quest for value. New York: Harper Business. 1091.

VAN HORNE, J ames. Financial management \& policy. 10th ed. London: Prentice Hall, 1995.

O autor agradece a Fundação de Amparo a Pesquisa do Estado de São Paulo - FAPESP e ao Conselho Nacional de Desenvolvimento Cientifico e Tecnológico - CNPq pelo apoio financeiro. 